Borquez, H.A., Wiegers, T.A.

A comparison of labour and birth experiences of women delivering in

a birthing centre and at home in the Netherlands.

Midwifery: 22, 2006, p.

\begin{tabular}{|c|c|}
\hline Postprint Version & 1.0 \\
\hline Journal website & http://www.sciencedirect.com \\
\hline Pubmed link & $\begin{array}{l}\text { http://www.ncbi.nlm.nih.gov/entrez/query.fcgi? } \mathrm{db}=\text { pubmed\&cmd=Retrieve\&dop } \\
\mathrm{t}=\text { AbstractPlus\&list uids=16647170\&query } \mathrm{hl}=1 \& \text { itool=pubmed docsum }\end{array}$ \\
\hline DOI & 10.1016/j.midw.2005.12.004 \\
\hline
\end{tabular}

\title{
A comparison of labour and birth experiences of women delivering in a birthing centre and at home in the Netherlands
}

HEATHER A. BORQUEZ, MS, RNC (2003-2004 FULbRight SCHOLAR) ${ }^{\mathrm{A},{ }^{*}}$, THERESE A. WIEGERS, PHD (SENIOR RESEARCHER) $^{\mathrm{B}}$

a Netherlands Institute for Health Services Research (NIVEL), PO Box 1568, 3500 BN, Utrecht, the Netherlands

b NIVEL, Utrecht, the Netherlands

* Corresponding author. E-mail address: haborquez@hotmail.com (H.A. Borquez).

\section{SUMMARY}

Objective: to compare the labour and birth experiences of women who delivered at home without complications with the experiences of women who delivered in a birth centre without complications.

Design: a descriptive study using postal questionnaires at 1-6 months after birth of a consecutive sample of postpartum women.

Setting: women were recruited from one birth centre and three midwifery practices in an urban area of the Netherlands between September and December 2003.

Participants: 193 women; 129 delivered at home and 64 delivered in the birth centre.

Findings: the home-birth group perceived less pain (mean score home birth 6.291, birthcentre birth 6.977), desired less pain-relieving medication (home birth 7.9\%, birth-centre birth $21.9 \%$ ), believed they knew their midwife better (home birth $36 \%$, birth-centre birth $10 \%$ 'knew her well'), and rated their birth setting 'higher' than the birth-centre group (mean score home birth 4.70, birth-centre birth 4.01).

Furthermore, the birth-centre group emphasised safety, having medical help available, and convenience, whereas the home-birth group placed more importance on the home being trustworthy and dependable, having their own place and belongings, and feeling comfortable and relaxed.

Key conclusions: having an understanding of a woman's labour and delivery experience allows health-care providers to continue to improve the quality of maternity care. The environment can have a positive effect on a woman's birth experience; recommendations have been proposed that can be applied to all pregnant and labouring women.

Implications for practice: identification and understanding of the factors in the environment that make the labour and birth experience more positive should be incorporated into the education and preparation for an upcoming birth. 
Borquez, H.A., Wiegers, T.A.

A comparison of labour and birth experiences of women delivering in

a birthing centre and at home in the Netherlands.

Midwifery: 22, 2006, p.

\section{INTRODUCTION}

Although most of the industrialised world has considered the hospital the safest and most appropriate place to birth since the 1940s (Ackermann- Liebrich et al., 1996), from a worldwide perspective, home birth is actually the norm, whereas hospital birth is the alternative. In the developed world, however, the home-birth rate has steadily decreased over the past 60 years (Wiegers et al., 1998; Kerssens, 1994). In response to these changes, researchers have sought to compare the two birth environments and identify which factors influence the birth experience.

Although the quality of care during labour has traditionally been studied through examining maternal and perinatal morbidity and mortality (Ackermann- Liebrich et al., 1996; Janssen et al., 2002), factors such as comfort, calmness and control of the environment can all affect the birth experience. With fewer maternal deaths and increasing awareness that perinatal mortality is not necessarily a result of a stressful labour or compromised care, it is necessary that we re-evaluate the quality of labour care. For a thorough yet unique view of a labour and birth experience, we must examine the experiences of women themselves (Smith, 2001). The purpose of this paper is to report and compare the perceptions of labour and birth experiences of healthy women choosing to deliver at home with healthy women choosing to deliver in a birth centre attached to a hospital. The findings have implications for midwives, obstetricians and nurses who care for labouring women. Health-care providers can gain insight into a woman's experience during the labour and delivery process, which will lead to improvement of the prenatal education and preparation for labour and birth. Finally, studying the Dutch obstetric model will give health-care providers in other countries some ideas about the values of Dutch women regarding home and birth-centre births, which could be incorporated into the labour care of childbearing women.

\section{Background}

Several studies comparing home and hospital birth have shown that home birth is just as safe as hospital birth (Ackermann-Liebrich et al., 1996; Wiegers et al., 1996; Olsen, 1997; Janssen et al., 2002) for both the mother and the baby. Researchers have found that fewer interventions and less medication were given to women who delivered at home compared with women who delivered in the hospital. Women who planned to deliver at home were also less likely to have an epidural, have an induced labour, have their labours augmented with oxytocin or prolactins, or have an episiotomy (Ackermann-Liebrich et al., 1996). Furthermore, rates of perinatal mortality, 5-min Apgar scores, meconium aspiration syndrome, and need for transfer to a specialised hospital were similar for the home and hospital births (Olsen, 1997).

Additional studies have explored various influences on birth experience. Lock and Gibb (2003) studied the relationship between birth setting and overall birth experience; they found that the feelings of women who entered the foreign place of the hospital to have their children were those of alienation and disempowerment, whereas women who delivered in the familiar territory of home reported stronger feelings of security and support. Green and Baston (2003) found that feeling in control during labour often correlates with a greater satisfaction with the birth experience. Van der Hulst et al. (2004) suggest that birth expectations and perceptions influence the actual birth process. Finally, Wagner (2001) stresses the importance of humanising birth and making certain a woman's childbirth experience is fulfilling and empowering. The aim of the study reported in this paper was to examine the childbirth experience in relation to the environment and determine whether there is a measurable difference in the perception of postpartum women's labour and birth experiences between two groups of women who delivered without complications: at home and in a birth centre.

\section{Dutch system}

This study was conducted in the Netherlands, as it is one of the few industrialised countries where planned home birth is still encouraged and accepted as the norm for healthy pregnant women. Two unique features of the Dutch obstetric system are the large number of home births and the relatively low rate of medical intervention. The rate of caesarean sections in the Netherlands is only $13.7 \%$ (CBS, 2003), compared with $21.3 \%$ in the UK (Thomas and Paranjothy, 2001), 26.1\% in the USA (CDC, 2002) and 22\% in Australia (AIHW, 2002). There is a clear division between primary care (midwives and general practitioners) and secondary care (obstetricians). Because pregnancy, labour and the postnatal period are considered normal physiologic events, women are encouraged to give 
Borquez, H.A., Wiegers, T.A.

A comparison of labour and birth experiences of women delivering in

a birthing centre and at home in the Netherlands.

Midwifery: 22, 2006, p.

birth at home instead of the hospital (Kerssens, 1994). One important feature of Dutch maternity care is risk selection: women with an increased risk of complications during pregnancy are referred to an obstetrician (secondary care) and will deliver in the hospital, whereas women who stay low risk throughout their pregnancy will be cared for by a primary-care giver: a midwife or a general practitioner. These women can choose to have a home birth or a short-term hospital birth (a short stay in the hospital for delivery, with the postpartum recovery period spent at home). Through screening and selecting women during pregnancy, midwives are able to work with a group of healthy women (Smulders, 1999). In the Netherlands, about $70 \%$ of births are attended by midwives (compared with only $7 \%$ in the USA), whereas the other $30 \%$ are attended by obstetricians. (Eltringham et al., 2005). Of the midwife-attended births, $60 \%$ take place at home and $40 \%$ occur in the hospital, which translates to $31.8 \%$ of all births taking place at home (CBS, 2003). Research has shown that, for women with low-risk pregnancies in the Netherlands, delivering at home is as safe as delivering in the hospital (Wiegers, 1998).

\section{METHODS}

\section{Selection of method}

The focus of this study was to compare childbirth experiences between two groups of postpartum women. For that reason, a survey approach afforded us the most participants in a short period of time. Furthermore, owing to time constraints of the grant that provided funding for this study, enrolment in the study was limited to 200 , thereby giving authors sufficient time to analyse all findings. Powercalculations showed that a sample of between 60 and 100 cases in each group was sufficient to detect a difference of $10 \%$ between scores on a 10 -point scale.

\section{Ethical considerations}

In the Netherlands, approval from a Research Ethics Committee to carry out research in which no interventions take place is not required. It is sufficient to explain to the potential participants that they are free to participate and that their privacy is guaranteed. Because no interventions took place in this study, ethics committe approval was not obtained. Researchers, however, did obtain permission from the directors of the birth centre and midwifery practices to send their clients a letter describing the study and its implications, along with a questionnaire. Letters were sent from the birth centre and midwifery practices directly and co-signed by the directors of the practices. The letter clearly explained that if a client did not want to participate, she was not obliged to return the questionnaire. By returning the finished questionnaire, clients consented to participating in the study. In two of the midwifery practices, consent was asked of the clients by the midwives, before researchers sent out the letters and questionnaires. Moreover, questionnaires and informative letters were sent directly from the birth centres; researchers did not have access to any of the clients' information (i.e. demographic information, addresses or identifying factors). Confidentiality was maintained as the researchers did not have the names and addresses of any of the women.

\section{Study participants}

This descriptive study was conducted in a large urban community in the Netherlands; participants lived within half an hour's drive from the city centre. Recruitment took place during a 12-week period in the autumn of 2003. Research has shown that women who had deliver vaginally report feeling stable up to 6 months postpartum (Cogan et al., 1988); we therefore included women who had delivered within the past 6 months. Women who were referred to secondary care because of problems during pregnancy (gestational diabetes, hypertension, preterm labour, induced labour, placenta praevia), problems during the immediate postpartum period (within $4 \mathrm{hrs}$ ) (postpartum haemorrhages, third or fourth degree lacerations, neonatal anomalies), or both, were excluded from the study. Consecutive sampling was used. Women who had a normal spontaneous vaginal delivery without complications (i.e. without referral), and who delivered between 1 and 6 months previously, were sent a questionnaire, along with a letter describing the purpose of the study and a stamped return envelope. Questionnaires were sent to two groups of postpartum women: those who delivered at home and those who delivered in the birth centre. The home-birth group consisted of women from three different 
Borquez, H.A., Wiegers, T.A.

A comparison of labour and birth experiences of women delivering in

a birthing centre and at home in the Netherlands.

Midwifery: 22, 2006, p.

midwifery practices, whereas the birth-centre birth group consisted of women who delivered at one birth centre located in the same region.

Midwifery practices varied in size from having three to five midwives. The birth centre used for this study is in a large academic hospital, which has a birthing centre staffed by nurses and midwives for low-risk deliveries, and an obstetrics unit staffed by nurses and physicians. The birthing centre is separate from the obstetrics department and is open 24 hrs a day. Women stay a few hours or just one night after their delivery before returning to their homes. In case of complications, the woman will be referred to secondary care and transferred to the obstetrics department in the same building, one level down. Questionnaires were only sent to women who delivered in the birthing centre, and who were not transferred to the obstetrics department.

\section{Questionnaire}

Before the study, a sample questionnaire was tested on 20 postpartum women in the USA in the spring of 2003, in order to determine validity. In addition, the translated questionnaire was tested on a sample of Dutch postpartum women in order to determine clarity and understandability. The questionnaire was then back translated into American English to ensure accuracy of translation.

The questionnaire consisted of five questions on characteristics (birth location, age, married or living with partner status, education and parity) and seven multiple choice or yes/no questions as follows: (1) if you were to have another baby, would you deliver at the same location?; (2) how well did you know the midwife who delivered your baby?; (3) overall, were you satisfied with the care the midwife provided for you?; (4) did you wish that something could be done to relieve your pain?; (5) did you receive something to relieve the pain?; (6) were you satisfied with the treatment?; and (7) immediately after the delivery, did you hold, breast or bottle-feed your baby?

The questionnaire also included five open-ended questions: (1) why did you choose to deliver where you did?; (2) what were your expectations for labour and delivery?; (3) what did you like about the place where you delivered?; (4) what did you dislike about the place where you delivered?; and (5) please describe your labour and delivery experience.

Two questions used a scale of 1-10: (1) please describe your pain on a scale of 1 (no pain) to 10 (very much pain); and (2) please rate your birth experience on a scale of 1 (very negative) to 10 (very positive). One question used a visual analogue scale (VAS): (1) please use a vertical line to mark your satisfaction with your birth experience on the line provided ('very good experience' vs. "very bad experience').

In four attitude questions, participants were asked to respond to each individual item using a bi-polar five-point scale ('not at all' to 'very much'): (1) please describe your feelings during labour; (2) please describe your feelings about your midwife during the delivery; (3) please describe your feelings about the place where you delivered; (4) in the event that your partner attended the birth, please describe your feelings about your partner during the labour and delivery.

About half of the items contained 'positive' descriptions, whereas the other half contained 'negative' descriptions of birth experience. Fivepoint scale attitude questions were grouped into categories according to topic, and a Cronbach's $\alpha$ of 0.70 or greater confirmed internal consistency that the individual items could in fact be grouped together and scored as a category. Items that favoured negative descriptions were reverse scored (i.e. $1=5,2=4,4=2$, and $5=1$ ), and a total attitude score was determined by computing the mean of the sum of responses to the individual items. Total attitude scores ranged from 1.3, reflecting a negative birth experience, to a high of 5.0, reflecting a positive birth experience.

\section{Data analysis}

All statistical data were entered into an SPSS data file. The relationship between socio-demographic factors and birth place was analysed using the independent t-test. Distributions for attitude scores were compared using the Mann-Whitney U test. Pearson's correlation was used to determine correlation. Open-ended questions were analysed using qualitative analysis techniques of grouping similar responses into various theme categories. The number of responses in each category was then totalled in order to derive a percentage of responses. 
Borquez, H.A., Wiegers, T.A.

A comparison of labour and birth experiences of women delivering in

a birthing centre and at home in the Netherlands.

Midwifery: 22, 2006, p.

\section{FINDINGS}

\section{General findings}

A total of 289 questionnaires were sent out, and 193 were received and used in the study, leading to a total response rate of $66.8 \%$ ( $77.7 \%$ in the homebirth group and $52.0 \%$ in the birth-centre group). As researchers did not have participants' names or addresses, reminder notes were not sent out. Age, marital status and education were consistent between the two groups. No difference was found in how each group rated their overall delivery experience, either on a 10-point scale or on the VAS, two different ways of measuring the same variable: overall birth experience. In this study population, primiparae were more likely to deliver in the birth centre than multiparae, which is consistent with other studies (Ackermann-Liebrich et al., 1996; Wiegers et al., 1996). Women in the home-birth group indicated more often that they would have their next baby in the same place. Lastly, a difference was found in the amount of pain the women experienced and the action they wanted for the pain. Women in the birth-centre group rated their pain higher and were more likely to want pain-relieving medication. No difference was found, however, in the amount of painrelieving medication each group received; only $1.6 \%$ of women in the entire study group received medication for the pain. See Table 1 for a comparison of this information.

\section{[ TABLE 1 ]}

\section{Midwife}

Both groups of postpartum women were highly satisfied with the care provided by their midwife. No difference was found in satisfaction rating or in attitude responses of women's feelings about the midwife during labour and delivery. However, a difference was found in how well the client knew the midwife before delivery. Women in the home-birth group were far more likely to have met their midwife before delivery, and also to have developed a relationship to the point where they believed they 'got to know the midwife very well before labour and delivery'. The relationship with the midwife between the birth-centre and homebirth groups is shown in Table 2.

\section{[ TABLE 2 ]}

\section{Birth setting}

With the use of a five-point Likert scale, a significant difference was found in how each group of women described their birth setting. The overall attitude score for birth setting was significantly different for each group, as well as in six out of the seven items within the category: safe, intimate, trust, comfortable, strange and anxiety-producing. Scores ranged from a low of 1 to a high of 5 . The mean scores of each group for all the items within the category of birth setting are listed in Table 3 . Furthermore, a positive correlation, significant at the 0.01 level for both groups, was found between the overall birth setting score and overall experience score (VAS) of labour and delivery for both groups. This indicates that the higher a woman rates her overall birth experience on the visual analogue, the more likely she is to rate her birth-setting higher.

\section{[ TABLE 3 ]}

\section{Data from open-ended questions}

Three open-ended questions from the questionnaire yielded noteworthy results: (1) why did you choose to deliver where you did?; (2) what did you like about the place where you delivered?; and (3) what did you dislike about the place where you delivered?

\section{Choice of birth environment}

In the birth-centre group, 19 women (30\%) reported choosing the birth centre because it was safe. 'I felt safer in the hospital'; 'good and safe feeling', 'safety', 'it gave me a safe feeling', and 'clean and safe' were cited as reasons for delivering in the birth centre. Seventeen (27\%) reported convenience: 'practical, at home I would have my three other children present', 'lived close to the hospital', 'not enough midwives in the area where I live who do home births'; 12 (14\%) women reported medical 
Borquez, H.A., Wiegers, T.A.

A comparison of labour and birth experiences of women delivering in

a birthing centre and at home in the Netherlands.

Midwifery: 22, 2006, p.

help available as their reason to deliver in the birth centre: 'felt more certain with all the provisions available'; 'to have medical help nearby in case it was necessary, in case of eventual complications'.

In the home-birth group, 44 (34\%) women used the Dutch word 'vertrouwd', which loosely translates to comfortable/trustworthy/dependable, to answer this question. 'Comfortable, dependable

environment', 'that is the most trustworthy', and 'my own home is the most dependable' were cited as reasons; 33 (26\%) chose home because it was cosy/comfortable/relaxed: 'easy to relax in your own home', 'I feel it is not stressful to deliver in my own environment', 'most comfortable environment before, during and after the delivery', 'I very much wanted to deliver at home because home is warmer and cosier than the hospital'; 28 (22\%) women who delivered at home placed importance on being in their own place with their own belongings: 'own place, own bed. Very nice!'; 'I very much wanted to deliver at home with my family in my own environment', and 'nice in my own environment with my own things' were reported; $22(17 \%)$ described home with feelings of familiarity and control: 'freedom to do what I wanted (go in bath, shower, stand, lie down)'; 'I could decide how I wanted to deliver', and 'home is familiar'. Finally, 21 (16\%) women reported that they had a positive past experience at home.

\section{Positive aspects of birth environment}

In the birth-centre group, 18 (28\%) women were pleased that medical help was available: 'all health provisions available', 'help nearby in case it was needed', and 'I was in good hands in case something went wrong'; 15 (23\%) described the care they received as good: 'good care and attention and professional guidance' and 'competent people, personal care'; $12(19 \%)$ liked the feeling that the hospital was safe; $10(16 \%)$ women enjoyed having their own room and bathroom in the hospital: 'room was only for one patient', 'nice big bathroom' and 'own shower and own toilet'. Lastly, nine women (14\%) liked feeling that the hospital was calm: 'it gave me a very calm feeling' and 'calm environment and nice atmosphere'.

In the home-birth group, 65 women (50\%) liked being in their own place with their own belongings: 'my own bed, my own shower', 'own things, own shower and toilet', 'that it was my own bedroom, my own shower, my rules', and 'home is my own environment'; 42 (33\%) liked the feeling that home was comfortable/trustworthy/dependable: 'the comfortable and dependable environment'. Twenty-five (20\%) responded that they could do what they wanted at home: 'I could do whatever I felt like, set a pot of tea, listen to music', 'I had the feeling that I had sufficient control over what I wanted to do: position, light, noise, etc.', and 'I could be myself', 22 (17\%) liked the convenience: 'other children could just sleep through the delivery', 'it seems annoying to me to have to sit in the car with contractions, to walk, to meet new people, and to get used to a new environment', and 'nicer for the other children that no one needed to leave'. Finally, 19 (15\%) liked it that home was calm and not stressful.

\section{Negative aspects of birth environment}

In the birth-centre group, 12 out of $64(32 \%)$ women did not answer the question and left it blank, and seven out of $52(14 \%)$ respondents answered 'nothing' in response to the question on what they disliked about where they delivered. Of those who filled in an answer, eight (15\%) found the hospital uncomfortable; six (12\%) disliked the fact that the birth attendant was very busy: 'I felt that the midwife and assistant were very busy' and 'I had to endure the contractions all alone since there was only one midwife for four deliveries'; five (9\%) respondents disliked having to leave the hospital soon after the birth: 'following the delivery, I had to leave my room very soon, quickly took a shower, and then was ready to go', 'about 3 hours after the delivery, needed to get out of bed again and get in the car to go home' and 'that I delivered at 10:55 pm and that at 2:30 am, I needed to go home again, since there wasn't any more space for me'. Lastly, four ( $8 \%$ ) respondents disliked having to travel to the hospital: 'that we needed to first drive there'.

In the home-birth group, 37 out of $129(29 \%)$ did not answer the question and left it blank and 35 of 92 (38\%) answered 'nothing'. Of those who answered the question, eight (9\%) disliked having no medical help available: 'the idea that I live on the 11th floor and that, in case of complications, would have to wait for the elevator', 'if there was something wrong with the baby, you don't have all the medical help at your finger tips' and 'no help if there was a problem with me or the baby'. Finally, 
Borquez, H.A., Wiegers, T.A.

A comparison of labour and birth experiences of women delivering in

a birthing centre and at home in the Netherlands.

Midwifery: 22, 2006, p.

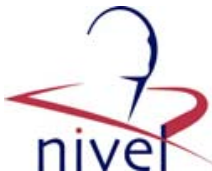

seven (8\%) described their place as too small: 'our bedroom is not really big enough for four people', 'the bedroom is a little too small and not air conditioned for the warmest day of the year!'

\section{DISCUSSION}

This was a retrospective study in which participants were not randomly assigned to a group. Because they chose the groups themselves, we can expect that the two groups of women were not equal from the start. Studies examining women's birth attitudes and reasons for choosing a particular place to deliver have found differences in women who chose to deliver at home compared with women who chose to deliver in a birth centre. Researchers (Cunningham, 1993; Ackermann-Liebrich et al., 1996; Longworth et al., 2001) have found that women delivering at home were older, more educated, more feminist, and more willing to accept responsibility for their health; these women were also found to have greater self determination, greater desire to influence and determine the birth themselves, and sought greater intimacy in the birth setting than women delivering in the hospital. The above mentioned studies, however, were conducted in countries in which home birth is considered an 'alternative' method of birthing; this could explain why women who are more educated and value making their own choices and decisions are more likely to be in the home-birth group. Although this study was conducted in the Netherlands, where home birth is considered the norm rather than the alternative, differences between women who choose home births compared with women who choose hospital births still exist. In a Dutch study, Wiegers (1998) found that, unlike the above mentioned studies, age and education were not determinants of choice between home and hospital births. Instead, societal factors and expectations of hospital care during childbirth were the strongest predictors of choice. Another Dutch study (van der Hulst, 2004), found that women who chose home birth had different expectations for birth and for themselves from women who chose hospital birth.

Moreover, it is necessary to be aware of the limitations of a survey approach, which takes for granted that participants have adequate reading and writing skills in order to understand the questions, and also have the motivation to devote the necessary time and energy to complete the form and return it. We can therefore assume that respondents are generally more educated than the population from which they were drawn, with consequent limitations on the degree to which these findings can be generalised to the group from which they were drawn.

Despite the study limitations, the findings have relevance to journal readers. First, it is important to reiterate that the study population included only healthy postpartum women who developed no complications during pregnancy or labour and delivery; this sample is therefore not representative of Dutch postpartum women as a whole. Only healthy women were chosen to avoid potential bias from women who were sent to the hospital because of complications, which could have a negative effect on their birth experience. Although no significant differences were found between the the birth-centre group and the home-birth group in characteristics or mean satisfaction scores, the fact the there is no difference is an important finding. Dutch women are equally satisfied with each labour and delivery experience, which may indicate that home births will continue to be a favourable and popular option, whereas the short-term hospital stay will also be a popular and accepted option for women who prefer to deliver in a birth centre. In this study, we found that more primiparae delivered in the birth centre than at home, and more multiparae delivered at home than in the birth centre. Although we cannot give a concrete explanation on the basis of our survey findings, we can hypothesise that this possibly indicates that, once a woman has had a normal, complication- free delivery and has an idea of what to expect for her next delivery, she may feel more comfortable in a setting away from a hospital. This may also explain why more women in the birth-centre group indicated wanting to have their next baby in a different place. Another interesting finding was that the birth-centre group rated their pain significantly higher than the home-birth group. These findings are consistent with those found in a study by Morse and Park (1988). A possible explanation for the higher rating of pain and increased desire for pain-relieving medication in the birth-centre group could be that there is less option for pain medication at home; at home, women may have a greater tolerance for pain because they know that if they want certain pain relievers (e.g. an epidural), they must travel to and deliver in the birth centre.

The difference in the relationship with the midwife between the home and birth-centre groups is likely to be due to the fact that the birth centre used in this study also employs its own midwives 
Borquez, H.A., Wiegers, T.A.

A comparison of labour and birth experiences of women delivering in

a birthing centre and at home in the Netherlands.

Midwifery: 22, 2006, p.

(although women may bring in their own midwife instead). For this reason, more women who delivered at the birth centre would be unfamiliar with their midwife.

Overall, the home-birth group rated their birth setting higher than the birth-centre group (Table 3). A higher birth setting score also correlates with a higher overall satisfaction score (VAS). Although the home-birth group rated home safer than the birth-centre group in a five-point Likert scale, women in the birth-centre group noted 'safety' as one of their most influential driving factors for delivering in the hospital in answering the open-ended questions. We may, therefore, infer that the birth-centre group was more preoccupied with safety before labour, whereas the home-birth group, in retrospect, determined their homes very safe.

\section{Recommendations}

Using the responses to the open-ended questions discussed above, the following recommendations are proposed to improve the birth setting (Box 1). These recommendations are intended for healthcare providers who care for the typical birthing woman in the developed world (i.e. complicationfree and not at home).

\section{CONCLUSION}

The perception of women's birth experiences is an important part of evaluating the labour and delivery process and outcome as a whole. By comparing two groups of healthy postpartum women and how they described their birth experiences in relation to their environment, we were able to determine various differences between the two birth settings. Although the two groups had similar characteristics and overall satisfaction, the home-birth group had perceivably less pain, desired less pain-relieving medication, believed they knew their midwife better, and rated their birth setting 'higher' than the birth-centre group. Furthermore, from the open-ended questions, we learned that the birthcentre group emphasised safety, medical help available and convenience, whereas the home-birth group placed more importance on the home being trustworthy and dependable, having their own place and belongings and feeling comfortable and relaxed. On the basis of the reasons cited by women in both groups, we have proposed recommendations that can be applied to pregnant and labouring women internationally. Having an understanding of a woman's labour and delivery experience allows healthcare providers to continue to improve the quality of maternity care. From this study, we have found that the environment can affect a woman's birth experience, and how we can apply certain positive features from the environment to each woman's labour and delivery.

\section{REFERENCES}

Ackermann-Liebrich, U., Voegeli, T., Gunter-Witt, K., et al., 1996. Home versus hospital deliveries: follow up study of matched pairs for procedures and outcome. British Medical Journal 313, 13131318.

Australian Institute of Health and Welfare, National Perinatal Statistics Unit, 2002.

CBS, 2003. Vademecum gezondheidsstatistiek Nederland 2003. Centraal Bureau voor de Statistiek, Voorburg, Heerlen.

Cogan, R., Perkowski, S., Anderson, D.A., 1988. Memories of labor and birth: reliability of post partum questionnaire reports. Perceptual and Motor Skills 67, 75-79.

Cunningham, J.D., 1993. Experiences of Australian mothers who gave birth either at home, at a birth centre, or in hospital labour wards. Social Science and Medicine 36, 475-483.

Eltringham, D., Gore, C., Malo, C. et al., 2005. Certified nurse midwives: as primary caregivers. www.pregnancyandbaby.com (last accessed 23 February 2006).

Green, J.M., Baston, H.A., 2003. Feeling in control during labor: concepts, correlates, and consequences. Birth 30, 235-247.

Janssen, P.A., Lee, S.K., Ryan, E.M., et al., 2002. Outcomes of planned home births versus planned hospital births after regulation of midwifery in British Columbia. Canadian Medical Association Journal 166, 315-323.

Kerssens, J.J., 1994. Patient satisfaction with home-birth care in the Netherlands. Journal of Advanced Nursing 20, 344-350.

Lock, L.R., Gibb, H.J., 2003. The power of place. Midwifery 19, 132-139.

Longworth, L., Ratcliffe, J., Boulton, M., 2001. Investigating women's preferences for intrapartum care: home versus hospital births. Health and Social Care in the Community 9, 404-413. 
Borquez, H.A., Wiegers, T.A.

A comparison of labour and birth experiences of women delivering in

a birthing centre and at home in the Netherlands.

Midwifery: 22, 2006, $p$

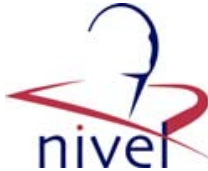

Morse, J., Park, C., 1988. Home birth and hospital deliveries: a comparison of the perceived painfulness of parturition. Research in Nursing and Health 11, 175-181.

Olsen, O., 1997. Meta-analysis of the safety of home birth. Birth 24, 4-16.

Smith, L.F.P., 2001. Development of a multidimensional labour satisfaction questionnaire: dimensions, validity, and internal reliability. Quality in Health Care: QHC 10, 17-22.

Smulders, B., 1999. The place of birth: the Dutch midwifery system. Birth International homepage; www.acegraphics.com.au (last accessed 31 January 2006).

Thomas, J., Paranjothy, S., 2001. National Sentinel Caesarean Section Autdit Report. Royal College of Obstetricians and Gynaecologists 17.

Van der Hulst, L., Teijlingen, E., Bonsel, G., et al., 2004. Does a pregnant woman's intended place of birth influence her attitudes toward and occurrence of obstetric intervention? Birth 31, 28-33.

Wagner, M., 2001. Fish can't see water: the need to humanize birth. International journal of gynaecology and obstetrics: the official organ of the International Federation of Gynaecology and Obstetrics 75, S25-S37.

Wiegers, T.A., Keirse, M.J.N.C., van der Zee, J., et al., 1996. Outcome of planned home and planned hospital births in low risk pregnancies: prospective study in midwifery practices in the Netherlands. British Medical Journal 313, 1309-1313.

Wiegers, T.A., 1998. Home or hospital birth: a prospective study of midwifery care in the Netherlands. European Journal of Obstetrics, Gynecology, and Reproductive Biology 79, 139-141.

Wiegers, T.A., van der Zee, J., Kerssens, J.J., et al., 1998. Home birth or short-stay hospital birth in a low risk population in the Netherlands. Social Science and Medicine 46, 1505-1511.

\section{TABLES AND BOXES}

Table 1 Overall findings.

\begin{tabular}{|c|c|c|c|c|c|c|c|}
\hline & \multicolumn{2}{|c|}{$\begin{array}{l}\text { Birth-centre } \\
\text { group }\end{array}$} & \multicolumn{2}{|c|}{$\begin{array}{l}\text { Home-birth } \\
\text { group }\end{array}$} & t-test and $\chi^{2}$ & $\mathrm{df}$ & $p$ \\
\hline Age: mean (sd) & 31.94 & $(5.4)$ & 32.52 & $(3.5)$ & $\mathrm{t}=0.78$ & 90.3 & 0.436 \\
\hline Satisfaction (scale 1-10): mean (sd) & 7.91 & $(1.6)$ & 8.06 & $(1.7)$ & $t=0.56$ & 188 & 0.577 \\
\hline Pain (1-10): mean $(\mathrm{sd})^{*}$ & 6.98 & $(2.1)$ & 6.29 & $(2.3)$ & $t=2.04$ & 189 & 0.043 \\
\hline \multirow[t]{2}{*}{ Overall experience (VAS 0-10): mean (sd) } & 8.14 & $(1.6)$ & 8.22 & $(1.9)$ & $t=0.26$ & 191 & 0.798 \\
\hline & $n$ & $\%$ & $n$ & $\%$ & & & \\
\hline Married/living with partner & 62 & 96.9 & 128 & 99.2 & $\chi^{2}=1.54$ & 1 & 0.214 \\
\hline With higher education (at least college) & 41 & 65.1 & 83 & 64.3 & $\chi^{2}=0.01$ & 1 & 0.920 \\
\hline First delivery* & 30 & 46.9 & 40 & 31.0 & $\chi^{2}=4.66$ & 1 & 0.031 \\
\hline Would have next baby in same place & 49 & 76.6 & 128 & 99.2 & $\chi^{2}=28.90$ & 1 & $<0.001$ \\
\hline Satisfied with care provided by midwife & 63 & 98.4 & 126 & 100.0 & $\chi^{2}=1.98$ & 1 & 0.159 \\
\hline Wanted something for the pain " & 14 & 21.9 & 10 & 7.9 & $\chi^{2}=7.59$ & 1 & 0.006 \\
\hline Received something for the pain & 2 & 3.2 & 1 & 0.8 & $\chi^{2}=1.57$ & 1 & 0.211 \\
\hline
\end{tabular}

*, Significant with $p<0.05$ on independent t-test or $\chi^{2}$ test (cases with missing data excluded). VAS, visual analogue scale.

Table 2 Relationship with midwife.

\begin{tabular}{lll}
\hline Relationship with midwife & Birth-centre group & Home-birth group \\
\hline $\begin{array}{l}\text { I never met the midwife before she delivered my baby } \\
\text { I had met the midwife before the delivery, but I did not know }\end{array}$ & $\begin{array}{l}71 \%(n=45) \\
\text { her very well }\end{array}$ & $\begin{array}{l}9 \%(n=12) \\
55 \%(n=70)\end{array}$ \\
$\begin{array}{l}\text { I had got to know the midwife who cared for me during labour } \\
\text { and delivery very well, before I went into labour }\end{array}$ & $10 \%(n=6)$ & $36 \%(n=46)$ \\
Total & $100 \%(n=63)$ & $100 \%(n=128)$ \\
\hline
\end{tabular}

$\chi^{2}=77.787 ; \mathrm{df}=2 ; p<0.001$ (cases with missing data excluded). 
Borquez, H.A., Wiegers, T.A.

A comparison of labour and birth experiences of women delivering in a birthing centre and at home in the Netherlands.

Midwifery: 22, 2006, p.

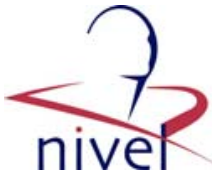

Table 3 Birth setting scores*.

\begin{tabular}{|c|c|c|c|c|}
\hline & $\begin{array}{l}\text { Birth-centre group } \\
\qquad(n=64)\end{array}$ & $\begin{array}{l}\text { Home-birth group } \\
\qquad(n=129)\end{array}$ & Mann-Whitney $U$ test & $p$ \\
\hline Overall Score $\dagger$ & 4.0 & 4.7 & 1390.500 & $<0.001$ \\
\hline Safe & 4.4 & 4.6 & 3333.000 & 0.021 \\
\hline Intimate $\dagger$ & 3.0 & 4.7 & 1136.000 & $<0.001$ \\
\hline Trust $†$ & 3.5 & 4.9 & 1180.000 & $<0.001$ \\
\hline Comfortablet† & 3.7 & 4.4 & 2298.500 & $<0.001$ \\
\hline Appropriate & 4.3 & 4.5 & 3478.500 & 0.167 \\
\hline Strange $\dagger$ & 1.6 & 1.1 & 2634.000 & $<0.001$ \\
\hline $\begin{array}{l}\text { Anxiety- } \\
\text { producing } \dagger\end{array}$ & 1.2 & 1.1 & 3520.00 & 0.021 \\
\hline
\end{tabular}

*,Participants were asked: 'please describe your feeling about the place where you delivered' (a score of $1=$ lowest possible score $=$ not agree at all; a score of $5=$ highest possible score $=$ totally agree); $\uparrow$, Mann-Whitney U test: significant for $p<0.05$.

\section{Box 1 Recommendations based on answers to the open-ended questions}

Familiarity:

Provide tours of the birthing setting (i.e. hospital) and rooms

Comfort

Encourage women to bring their own personal belongings

Ensure that birth setting has comfortable place to deliver (i.e. bed, shower, bath, stool), and that women are given the option of how and where they would like to deliver

Ensure a comfortable postpartum/recovery area (i.e. bed, chairs)

Intimacy

Limit flow of people in and out of birthing room

Try to maintain consistency with health-care providers from beginning to end of labour

Encourage women to invite family and friends for support

Provide the opportunity for rooming-in for women's support person/partner

Provide women with private delivery and postpartum room

Control

Give women options about food, drink, how and where they would like to deliver

Calmness

Decrease noise Decrease flow of people. 